\title{
HUBUNGAN PERSEPSI DAN TINGKAT PENGETAHUAN PENDERITA TB DENGAN KEPATUHAN PENGOBATAN DI KECAMATAN BULELENG
}

\author{
Made Suadnyani Pasek ${ }^{1}$, I Made Satyawan ${ }^{2}$ \\ 1,2 Jurusan Pendidikan Jasmani, Kesehatan dan Rekreasi, Fakultas Olahraga dan Kesehatan \\ Universitas Pendidikan Ganesha, Singaraja, Indonesia.
}

\begin{abstract}
Abstrak
Penelitian ini bertujuan untuk menganalisis persepsi dan tingkat pengetahuan penderita TB dengan kepatuhan pengobatan yang dapat memberikan kontribusi terhadap suksesnya pelaksanaan program TB di Kecamatan Buleleng. Jenis penelitian ini adalah penelitian observasional analitik dengan pendekatan cross sectional bersifat retrospektif. Populasi penelitian 216 orang, sampel sebanyak 40 orang yang didapatkan dengan mengunakan teknik random sampling. Data didapatkan dengan memberikan kuisioner kepada responden yang kemudian dianalisis dengan uji analisis regresi logistik ganda. Pada taraf signifikansi $p$ $=0,05$ diperoleh nilai persepsi $(p=0,022, O R=11.930, \mathrm{Cl} 95 \%=1.429$ hingga 99.603) dan tingkat pengetahuan $(p=0,017 ; O R=19.714 ; C l 95 \%=1.696$ hingga 229.173). Simpulan dari penelitian ini terdapat hubungan yang signifikan antara persepsi dan tingkat pengetahuan penderita TB dengan kepatuhan pengobatan, dimana penderita dengan persepsi dan tingkat pengetahuan baik memiliki kepatuhan pengobatan.
\end{abstract}

Kata-kata kunci: Persepsi, Tingkat Pengetahuan, Kepatuhan Pengobatan

\begin{abstract}
The aim of this research is to know the correlation among perception and knowledge of TB patients with medication compliance. This study was an observational analytic research. The number of population that were used in this study were 216 people and the the number of the sample in this study were 40 people, drawn by simple random sampling technique. The level of perceptions and knowledge were obtained dari the questionaire given to the sample and the level were tested by logistic regression analysis. In The level of significancy $p=0,05$ shows that the value of perception significantly influences the compliance of treatment $(p=$ $0,022, \mathrm{OR}=11.930, \mathrm{Cl} 95 \%=1.429$ to 99.603 ) and the value of knowledge also significantly influences the treatment $(p=0,017 ; O R=19.714 ; \mathrm{Cl} 95 \%=1.696$ to 229.173). The conclusion, there is correlation between the perception and the level of knowledge of TB patients with medication compliance in which the perception of positive and good knowledge of TB patients are likely to be obedient in the treatment
\end{abstract}

Keywords: Perception, Knowledge Level, TB Treatment Compliance

\section{PENDAHULUAN}

Tuberkulosis (TB) adalah penyakit menular langsung yang disebabkan oleh kuman Mycobacterium tuberculosis. TB merupakan salah satu masalah kesehatan yang utama (Nurhayati,2011). Berdasarkan data yang terdapat di Puskesmas Buleleng I, II dan III, pada tahun 2009 jumlah penderita TB yang terdiagnosa melalui pemeriksaan dahak dan rontgen mencapai 150 orang dan pada tahun 2011 jumlah tersebut meningkat menjadi 216 orang.
Pengobatan penyakit TB memerlukan waktu selama 6 bulan, dan selama masa pengobatan tersebut, banyak penderita yang menghentikan pengobatan di tengah jalan. Banyak faktor yang berpengaruh terhadap keberhasilan pengobatan TB antara lain kepatuhan, pendidikan, persepsi, status sosial ekonomi penderita, petugas kesehatan di puskesmas.

Masih banyak penderita TB yang berhenti di tengah jalan karena interpretasi yang salah mengenai penyakitnya, 
menganggap penyakitnya sudah sembuh. Hal ini kemungkinan disebabkan karena pengetahuan yang masih kurang dan persepsi atau cara memandang penyakit TB masih negatif. Persepsi pada hakikatnya adalah merupakan proses penilaian seseorang terhadap obyek tertentu. Menurut Young (dalam Gunadarma, 2011) persepsi merupakan aktivitas mengindera, mengintegrasikan dan memberikan penilaian pada obyek-obyek fisik maupun obyek sosial, dan penginderaan tersebut tergantung pada stimulus fisik dan stimulus sosial yang ada di lingkungannya. Sensasisensasi dari lingkungan akan diolah bersama-sama dengan hal-hal yang telah dipelajari sebelumnya baik hal itu berupa harapan-harapan,nilai-nilai, sikap, ingatan dan lain-lain.

Pendidikan mempengaruhi keteraturan minum obat pasien. Semakin tinggi tingkat pendidikan pasien, maka semakin banyak informasi tentang pengobatan yang diterimanya sehingga pasien akan patuh dalam pengobatan penyakitnya (Muhlisi, 2011). Faktor yang mempengaruhi tingkat kepatuhan menurut Smet (Dalam Cramer, 1991), adalah faktor komunikasi, pengetahuan, fasilitas kesehatan, faktor penderita termasuk persepsi dan motivasi individu. Gabit (1999) menjelaskan bahwa ada hubungan antara kepatuhan dengan kepercayaan terhadap beratnya penyakit, bahaya penyakit, manfaat pengobatan dan biaya. Masalah pada penelitian ini adalah 1), Apakah ada hubungan persepsi tentang penyakit TB dengan kepatuhan pengobatan? 2) Apakah ada hubungan tingkat pengetahuan penderita TB tentang penyakit TB dengan kepatuhan pengobatan? 3) Apakah ada hubungan persepsi dan tingkat pengetahuan penderita TB dengan kepatuhan pengobatan di Kecamatan Buleleng? Rencana pemecahan masalah adalah dengan membuat kuesioner untuk mengumpulkan data mengenai tingkat pengetahuan dan persepsi penderita TB mengenai penyakit TB. Setelah terdapat kuesioner, kemudian dilakukan proses pengumpulan data, reduksi data dan penarikan kesimpulan. Dari kesimpulan yang didapatkan kemudian dilakukan interpretasi. Dengan mengikuti proses penelitian ini, maka keluaran penelitian yang didapat adalah tentang hubungan persepsi dan tingkat pengetahuan TB dengan kepatuhan pengobatan TB. Tujuan penelitian ini adalah menganalisis hubungan persepsi dan tingkat pengetahuan penderita TB dengan kepatuhan pengobatan yang dapat memberikan kontribusi terhadap suksesnya pelaksanaan program TB di Kecamatan Buleleng

\section{METODE PENELITIAN}

Lokasi penelitian adalah di Kecamatan Buleleng. Penelitian ini merupakan penelitian observasional analitik dengan pendekatan cross sectional bersifat retrospektif. Populasi Penelitian adalah Penderita TB yang terdiagnosa melalui pemeriksaan sputum maupun rontgen thorax di Kecamatan Buleleng. Jumlah populasi adalah 216 orang dan sampel dalam penelitian ini diambil dengan teknik random sampling.

Berdasarkan perhitungan jumlah sampel, maka besar sampel dalam penelitian ini adalah 40 orang. Variabel penelitian terdiri dari variabel bebas yaitu persepsi tentang penyakit TB dan pengetahuan tentang penyakit TB. Variabel terikat yaitu kepatuhan pengobatan TB. Alat Pengumpul data untuk persepsi dan pengetahuan berupa kuesioner. Uji validitas dan reliabilitas instrumen dilakukan dengan uji korelasi dan reliabilitas dengan menggunakan alpha cronbach. Skor berdasarkan jawaban angket yang diserahkan kepada responden. Persepsi dikatakan positif bila skor lebih besar dari 70 dan dikatakan persepsi negatif bila skor lebih kecil atau sama dengan 70 . Pengetahuan dikatakan baik skor lebih besar dari 70 dan dikatakan tidak baik bila kurang atau sama dengan 70. Untuk indikator kepatuhan pengobatan adalah penderita yang melaksanakan pengobatan 
atau minum obat secara terus-menerus setiap hari selama enam bulan. Teknik analisis data dilakukan dengan bantuan komputer dengan menggunakan perangkat lunak program SPSS 16.0. untuk mengukur hubungan antara variabel bebas, variabel terikat secara bersama-sama dengan menggunakan uji analisis regresi logistik ganda.

\section{HASIL DAN PEMBAHASAN}

Tabel1. Distribusi Tingkat Pendidikan Responden TB di Puskesmas, Kecamatan Buleleng, Tahun 2012

\begin{tabular}{ccc}
\hline TK Pendidikan & Jumlah & Persentase \% \\
\hline SD & 9 & 22,5 \\
SMP & 15 & 37,5 \\
SMA & 12 & 30.0 \\
Diploma/Sarjana & 4 & 10,0 \\
Total & 40 & 100,0 \\
\hline
\end{tabular}

Dari tabel di atas dapat dijelaskan bahwa tingkat pendidikan penderita TB di wilayah kerja Puskesmas Buleleng yang paling banyak adalah setingkat SMP sebanyak 15 orang atau $37,5 \%$.
Berdasarkan hasil penelitian didapatkan skor persepsi tertinggi adalah 100 dan terendah adalah 43,33 dengan mean 79,01.

Tabel 2. Crosstab persepsi dengan kepatuhan

\begin{tabular}{|c|c|c|c|c|}
\hline & & \multicolumn{2}{|c|}{ kepatuhan } & \multirow[b]{2}{*}{ Tota } \\
\hline & & tidak patuh & patuh & \\
\hline \multirow[t]{3}{*}{ persepsi } & persepsi negatif & 6 & 7 & 13 \\
\hline & persepsi positif & 2 & 25 & 27 \\
\hline & Total & 8 & 32 & 40 \\
\hline
\end{tabular}

Berdasarkan tabel di atas dapat dijelaskan bahwa penderita yang memiliki persepsi negatif sebesar 13 orang dan yang memiliki persepsi positif sebesar 27 orang. Penderita yang memiliki persepsi positif lebih patuh terhadap pengobatan TB.

Tabel 3. Distribusi Frekuensi Tingkat Pengetahuan TB

\begin{tabular}{ll}
\hline $\mathrm{N} \quad$ Valid & 40 \\
\multicolumn{1}{c}{ Missing } & 0 \\
\hline Mean & 72.1429 \\
Minimum & 21.43 \\
Maximum & 100.00 \\
\hline
\end{tabular}

Berdasarkan tabel di atas didapatkan skor terendah adalah 21,43 dengan mean 72,14. pengetahuan tertinggi adalah 100 dan 
Tabel 4. Crosstab Pengetahuan dan Kepatuhan

\begin{tabular}{lllll}
\hline & & \multicolumn{3}{c}{ Kepatuhan } \\
\cline { 2 - 5 } & & tidak & \\
& patuh & patuh & Total \\
\hline pengetahuan & pengetahuan tdk baik & 7 & 9 & 16 \\
\cline { 2 - 5 } & pengetahuan baik & 1 & 23 & 24 \\
\hline Total & & 8 & 32 & 40 \\
\hline
\end{tabular}

Berdasarkan tabel 4 dapat dijelaskan bahwa penderita yang memiliki tingkat pengetahuan tidak baik sebanyak 16 orang dan yang memiliki tingkat pengetahuan baik sebanyak 24orang. Penderita yang memiliki tingkat pengetahuan baik lebih patuh terhadap pengobatan TB. Hal ini terlihat dari jumlah penderita yang memiliki tingkat pengetahuan baik yang patuh terhadap pengobatan sebanyak 23 orang, sedangkan yang tidak patuh dan memiliki tingkat pengetahuan tidak baik sebanyak 9 orang.

Tabel 5. Hasil Analisis Regresi Logistik Ganda Hubungan antara Persepsi Penderita TB dengan Kepatuhan minum obat

\begin{tabular}{lcclc}
\hline Variabel & OR & $\begin{array}{c}\text { Signifikansi } \\
(\mathrm{p})\end{array}$ & \multicolumn{2}{c}{$\begin{array}{c}\text { Confidence Interval } \\
\text { 95\% }\end{array}$} \\
\cline { 3 - 5 } & & & $\begin{array}{l}\text { Batas } \\
\text { Bawah }\end{array}$ & $\begin{array}{c}\text { Batas } \\
\text { Atas }\end{array}$ \\
\hline Persepsi & 11, & 0,022 & 1.429 & 99.603 \\
\hline N Observasi & 930 & & & \\
-2 log likelihood & $=40.032$ & & \\
Nagelkerker $\mathrm{R}^{2}$ & $=52,5 \%$ & & & \\
\hline
\end{tabular}

Berdasarkan tabel di atas, diketahui bahwa nilai OR didapatkan sebesar 11,930. Hal ini berarti bahwa penderita yang mempunyai tingkat persepsi tinggi mempunyai kemungkinan patuh minum obat 11,930 kali lebih tinggi daripada penderita yang tingkat persepsinya rendah. Hubungan tersebut secara statistik signifikan $(\mathrm{p}=$ 0,$022 ; \mathrm{OR}=11,930 ; \mathrm{Cl} 95 \%=1.42$ hingga 99.603).
Berdasarkan tabel 6, diketahui bahwa nilai OR didapatkan sebesar 19.714. Hal ini berarti bahwa penderita yang mempunyai tingkat pengetahuan tinggi mempunyai kemungkinan patuh minum obat 19.714 kali lebih tinggi daripada penderita yang tingkat pengetahuannya rendah. Hubungan tersebut secara statistik signifikan $(p=0,017 ;$ OR $=19.714 ; \mathrm{Cl} 95 \%=1.696$ hingga 229.173). 
Tabel 6. Hasil Analisis Regresi Logistik Ganda Hubungan antara Pengetahuan Penderita TB dengan Kepatuhan minum obat

\begin{tabular}{lllll}
\hline Variabel & OR & $\begin{array}{c}\text { Signifikansi } \\
(\mathrm{p})\end{array}$ & \multicolumn{2}{l}{$\begin{array}{l}\text { Confidence } \\
\text { Interval 95\% }\end{array}$} \\
\cline { 3 - 5 } & & & $\begin{array}{l}\text { Batas } \\
\text { Bawah }\end{array}$ & $\begin{array}{l}\text { Batas } \\
\text { Atas }\end{array}$ \\
\hline Pengetahuan & 19.714 & 0,017 & 1.696 & 229.17 \\
& & & & 3 \\
\hline N Observasi & $=40$ & & & \\
-2 log likelihood & $=40.032$ & & \\
Nagelkerker $\mathrm{R}^{2}$ & $=52,5 \%$ & & \\
\hline
\end{tabular}

Berdasarkan hasil regresi logistik berganda pada tabel di atas untuk mengetahui hubungan antara persepsi dan tingkat pengetahuan penderita TB secara simultan dengan kepatuhan pengobatan dapat dijelaskan bahwa ada hubungan yang signifikan persepsi dan tingkat pengetahuan penderita TB dengan kepatuhan pengobatan di Kecamatan Buleleng. Berdasarkan nilai koefisien determinan atau Nagelkerger $R$ Square diketahui sebesar 0,525, hal ini dapat dijelaskan bahwa pengaruh variabel persepsi dan tingkat pengetahuan penderita TB memberi pengaruh terhadap kepatuhan pengobatan sebesar $52,5 \%$, sedangkan pengaruh faktor lain yang tidak diteliti dalam penelitian ini sebesar $47,5 \%$.

\section{PEMBAHASAN}

Dari data yang diperoleh melalui kuesioner, maka peneliti membahas permasalahan yang ada sesuai denagan hipotesis penelitian.

1. Terdapat hubungan antara persepsi dengan kepatuhan pengobatan TB

Dalam penelitian ini, setelah dilakukan uji regresi logistik, maka didapatkan hubungan yang signifikan antara persepsi dan kepatuhan pengobatan. Penderita TB yang memiliki persepsi positif mengenai TB memiliki kemungkinan untuk patuh dalam pengobatan 11, 93 kali lebih besar daripada penderita TB yang memiliki persepsi negatif. $(\mathrm{OR}=11,93$, CI95\% 1,42 hingga 99,60).
Temuan ini sesuai dengan tinjauan teoritik. Persepsi positif mengenai penyakit TB meningkatkan kepatuhan penderita TB terhadap pengobatan TB. Persepsi merupakan suatu proses yang didahului oleh penginderaan, yaitu suatu stimulus yang diterima oleh individu melalui alat reseptor yaitu indera. Alat indera merupakan penghubung antara individu dengan dunia luarnya. Persepsi merupakan stimulus yang diindera oleh individu, diorganisasikan kemudian diinterpretasikan sehingga individu menyadari dan mengerti tentang apa yang diindera.

Persepsi sangatlah dipengaruhi oleh konsep yang dibuat pasien terhadap penyakitnya. Konsep tersebut berupa pemahaman. Proses memahami diartikan dapat menginterpretasikan obyek secara benar (Notoatmojo, 2003). Persepsi seseorang dalam menangkap informasi dan peristiwa-peristiwa menurut Kotler (Gunadarma, 2011) dipengaruhi oleh tiga faktor, yaitu: orang yang membentuk persepsi itu sendiri, khususnya kondisi intern (kebutuhan, kelelahan, sikap, minat, motivasi, harapan, pengalaman masa lalu dan kepribadian, yang kedua adalah stimulus yang berupa obyek maupun peristiwa tertentu (benda, orang, proses dan lain-lain), dan yang terakhir adalah stimulus dimana pembentukan persepsi itu terjadi baik tempat, waktu, suasana (sedih, gembira dan lain-lain).

Menurut penelitian yang dilakukan Erawatiningsih (2005) yang berjudul Faktor- 
Faktor yang Mempengaruhi Ketidakpatuhan Berobat Pada Penderita Tuberkulosis di Wilayah Kerja Puskesmas Dompu Barat didapatkan hasil bahwa faktor persepsi penderita TB mengenai penyakit TB, pengobatan dan konsekwensi bila pengobatan tidak dilakukan secara benar berpengaruh terhadap kepatuhan pengobatan TB. Penderita TB yang memiliki persepsi baik cenderung akan patuh dalam pengobatan TB.

Kurangnya pemahaman pasien akan pentingnya pengobatan, akibat yang ditimbulkan bila pengobatan tidak dilakukan secara tuntas akan mempengaruhi kepatuhan pengobatan. Hal ini juga berkaitan dengan sedikitnya informasi yang diterima oleh penderita TB mengenai penyakit TB. Hal ini akan mengakibatkan penderita TB akan mengembangkan pemahaman dan harapan dari sudut pandang mereka sendiri.

Pasien akan menjadi tidak patuh dalam pengobatan apabila pemahaman dan harapan mereka mereka mengenai pengobatan TB tidak sesuai dengan apa yang mereka dapatkan (Mukhsin, 2011)

2. Terdapat Hubungan Antara Tingkat Pengetahuan dan Kepatuhan Pengobatan TB

Hasil uji regresi logistik mengenai hubungan tingkat pengetahuan dan kepatuhan pengobatan TB didapatkan hubungan yang signifikan antara tingkat pengetahuan dan kepatuhan pengobatan. Penderita TB yang memiliki tingkat pengetahuan baik mengenai TB memiliki kemungkinan untuk patuh dalam pengobatan 19,71 kali lebih besar daripada penderita TB yang memiliki pengetahuan tidak baik (OR $=19,71, \mathrm{Cl} 95 \%$ 1,69 hingga 229,17).

Menurut Notoatmojo

(2003) pengetahuan merupakan hasil "tahu" dan ini terjadi setelah orang melakukan pengindraan terhadap suatu subyek tertentu. Pengindraan terjadi melalui panca indra manusia yaitu indra penglihatan, pendengaran penciuman, rasa, dan raba.
Pengetahuan atau kognitif merupakan domain yang sangat berperan untuk terbentuknya suatu tindakan seseorang. Berdasarkan pengalaman dan penelitian ternyata perilaku yang didasari oleh pengetahuan akan lebih langgeng dari pada perilaku yang tidak didasari oleh pengetahuan (Notoatmodjo, 2003).

Pengalaman merupakan salah satu faktor yang dapat mempengaruhi pengetahuan yang berkaitan dengan umur dan pendidikan individu. Hal ini mengandung maksud bahwa semakin bertambahnya umur dan pendidikan yang tinggi, maka pengalaman seseorang akan lebih jauh lebih luas. Mereka yang telah mengalami penyakit yang sama atau orang yang mereka kenal terutama TB akan memberikan pengetahuan yang lebih dibandingkan mereka yang belum pernah mengalaminya.

Kepatuhan adalah kesesuaian antara perilaku pasien dengan ketentuan yang diberikan obat sesuai jangka waktu yang ditentukan dan rutin kontrol ke Instansi Kesehatan. Lamanya proses pengobatan kadang membuat penderita jenuh sehingga beresiko mengalami putus obat yang bisa menjadikan pengobatan tidak tuntas hingga akhirnya penderita sulit disembuhkan. Pengetahuan penderita TB mengenai penyakit TB, pengobatan yang diperlukan dan lamanya pengobatan yang harus dilakukan mempengaruhi kepatuhan penderita untuk berobat secara tuntas. Hal ini sejalan dengan penelitian yang dilakukan oleh Mukhsin (2011) yang berjudul FaktorFaktor Yang Mempengaruhi Keteraturan Minum Obat Pada Penderita TBC Paru Yang Mengalami Konversi Di Kota Jambi, didapatkan hasil bahwa pendidikan, pengetahuan,dan sikap menunjukkan adanya hubungan yang signifikan dengan kepatuhan berobat pada penderita TB paru, demikian pula pendapat penderita terhadap kualitas pelayanan dari PMO ada hubungan yang signifikan dengan kepatuhan berobat pada penderita TB paru di kota Jambi.

3. Ada hubungan persepsi dan tingkat 
pengetahuan dengan kepatuhan pengobatan

Berdasarkan uji regresi logistik didapatkan hasil bahwa persepsi dan tingkat pengetahuan memiliki hubungan yang signifikan terhadap kepatuhan pengobatan TB.

Menurut Skinner (dalam Purwanta, 2006) perilaku kesehatan (health behavior) termasuk kepatuhan dalam menjalankan pengobatan adalah respons seseorang terhadap stimulus atau objek uang berkaitan dengan sehat-sakit,penyakit, dan faktorfaktor yang mempengaruhi sehat-sakit (kesehatan). Smet (dalam Cramer, 1991) mendefinisikan kepatuhan(ketaatan) sebagai tingkat penderita melaksanakan cara pengobatan dan perilaku yang disarankan oleh dokternya atau yang lain.

\section{KESIMPULAN}

Kesimpulan yang dapat ditarik dari penelitian ini adalah adanya hubungan yang signifikan antara persepsi dan TB dengan kepatuhan pengobatan TB.

1. Makin tinggi tingkat persepsi penderita terhadap TB maka akan semakin tinggi kepatuhan terhadap pengobatan TB dari pada penderita dengan persepsi yang rendah $(\mathrm{OR}=11,93, \mathrm{p}=0,022)$.

2. Makin tinggi pengetahuan penderita terhadap TB maka akan semakin tinggi kepatuhan penderita terhadap pengobatan TB dari pada penderita dengan pengetahuan yang rendah $(\mathrm{OR}=$ $19,71, p=0,017$ ).

3. Secara simultan semakin tinggi persepsi dan pengetahuan penderita terhadap TB maka akan semakin tinggi kepatuhan penderita terhadap pengobatan TB (Nagelkelker $R^{2}=52,5 \%$ )

\section{SARAN}

1. Kepada Penderita TB

Masyarakat diharapkan membuka wawasannya untuk menerima informasi mengenai kesehatan, kususnya mengenai penyakit TB sehingga mereka dapat menghindarkan diri agar tidak tertular penyakit tersebut. Kepada penderita dan keluarga hendaknya lebih aktif dan saling mengingatkan agar penderita terus minum obat sampai dinyatakan sembuh.

2. Kepada Petugas Medis

Petugas medis juga harus berperan aktif dalam memberikan informasi kesehatan mengenai penyakit menular kususnya penyakit TB, baik melalui penyuluhan maupun dengan brosur. Dengan ini diharapkan masyarakat lebih waspada dan ikut aktif untuk mencegah terjadinya penularan TB. Disamping itu kepada petugas $\mathrm{PMO}$ juga lebih aktif dan tetap menjaga komunikasi dengan keluarga penderita agar penderita tidak sampai putus minum obat (drop out).

\section{DAFTAR PUSTAKA}

Erawatiningsih, (2005). Faktor-Faktor yang Mempengaruhi Ketidakpatuhan Berobat Pada Penderita Tuberkulosis di Wilayah Kerja Puskesmas Dompu Barat. Dari : http://isjd.pdii.lipi.go.id /admin/jurnal/25309117124.pdf.

Diakses tanggal 10 September 2011.

Cramer. (1991). Compliance and MedicalPractice Clinical Trial. Dari http://www.pudmed.guv. Diakses tanggal 6 Juni 201.

DepKes RI. (2006). Pedoman Pemberantas Penyakit Tuberkulosis Paru. Ditjen PPM dan PLP. Jakarta: DepKes RI.

------, (2006). Pedoman Nasional Penaggulangan Tuberkulosis. Cetakan Ke-5. Jakarta: DepKes RI.

Gabit. (1999). Improving Complient by Gabit Ismailov Dunst. Dari http://www.dcc2. bumc.bu.ed/world.TB diakses tanggal 10 Juni 2011.

Gunadarma.(2011). Psikologi Umum. Dari http://elearning.gunadarma.ac.id/doc modul/psikologi umum 1/Bab 3.pdf. diakses tanggal 5 Juli 2011.

Jurnal Pendidikan Indonesia | 151 
Jurnal Respirologi Indonesia, (2011).Multi Drug Resistance (MDR) Pada Tuberkulosis.Dari

:http://jurnalrespirologi.org/jurnal/APRI L\%20VOL 30\%20NO 2\%202010.pdf . . Diakses tanggal 11 Februari 201.

Muhlisi, (2011). Pengaruh Gender Terhadap Kepatuhan Minum Obat Penderita Tuberkulosis Dengan Menggunakan Program DOTS di Kabupaten Purworejo. Tesis Pascasarjana. IKM UGM. Dari http://Irc-kmpk. UGM.ac.id/ id/UP-PDF/working/No.12

Herijon1007WPS.pdf .Diakses tanggal 5 Juli 2011.

Mukhsin. (2011). Faktor-Faktor Yang Mempengaruhi Keteraturan Minum Obat Pada Penderita TBC Paru Yang Mengalami Konversi Di Kota Jambi. Tesis Pasca Sarjana. IKM UGM. Dari
http://Irc-kmpk.UGM. ac.id/id/UP-PDF/ working/No.12 Herijon1007WPS.pdf. Diakses tanggal 6 Juli 2011.

Notoatmodjo S. (2003). Konsep Perilaku Kesehatan Buku Promosi Kesehatan Teori dan Aplikasi. Jakarta : PT Rineka Cipta.

Nurhayati. (2011). Referat Tuberkulosis. Dari http://www.scribd.com/doc 142860551/Referat-TBC. Diakses tanggal 10 Juni 2011.

Purwanta.(2006). Ciri-ciri Pengawas Minum Obat. Dari http://www.tbcindonesia. or.id.Diakses tanggal 23 Juni 2011.

Robert. (1999). Enhancing Medication Compliance for People. Dari http://www.drh.state.ga.us.ep/pdf/tb.gu ide.pdf. Diakses tanggal 20 Juni 2007. 